\title{
Assembly the Semantic Cultural Heritage Knowledge
}

\author{
Cokorda Pramartha ${ }^{a 1}$ \\ aDepartment of Computer Science, Udayana University \\ Bali, Indonesia \\ 1'cokorda@unud.ac.id
}

\begin{abstract}
This project aims to assembly the semantic cultural heritage knowledge dealing with one aspect of Balinese heritage, the kulkul system. We discuss our method and procedures to realize the goal of the project. The significant contribution of cultural heritage expert resulted in the kulkul specification and features. Also, the involvement of a knowledgeable community helped us to expand and validate the kulkul ontology. Finally, the cultural heritage knowledge was made available in the form of ontology to represent the knowledge that can be processed and manipulated by the computer program.
\end{abstract}

Keywords: Balinese kulkul, digital heritage, digital portal, ontology, living cultural repository

\section{Introduction}

The cultural knowledge erosion is still continuing today when the younger generation does not have any access to the traditional knowledge resources, and a limited process to learn about their heritage. The heritage refers to an intellectual or spiritual legacy that parents hand to the younger generation, their children [1]. Furthermore, cultural heritage is an aspect of past experience that carries an important value for a society, and continues to change dynamically with time [2,3]. It is a form of a man-made heritage that is often context-rich and therefore evolves through a long and complex process rather than by a single action or creation $[2,4,5]$.

Today, the digital cultural heritage resources open new pathways for the scholars, members of the community, and the younger generation in particular to represent, store, refine, maintain, share and then by contributing to further development of cultural heritage. In the digital heritage domain, much of the current research focuses on the tangible aspects of cultural heritage preservation, such as 3D reconstruction and visualisation, virtual reality, and augmented reality, whereas in many cases aspects of physical (e.g. artefacts and sites) and intangible (traditions and practices) cannot be separated.

In this research we focused on gathering, preserving, documenting, and safeguarding an element of cultural heritage with diverse cultural practices using digital technologies. We transformed the cultural knowledge and related practices into an explicit and digital form, in order for the public to add, refine, and further share the heritage. Additionally, our research was conducted in the domain of which Balinese cultural heritage that is rich and diverse with a range of unique traditions, practices, and artefacts, specifically the Balinese kulkul. The Balinese kulkul is part of the Balinese traditional communication system and varies from one village to another. The kulkul system consists of two aspects of physical (artefact) and intangible (practices) that cannot be separated. The kulkul artefact is an artefact in the form of a slit drum that mainly made of wood or bamboo tubes and are installed in a bale kulkul (kulkul pavilion), typically around temple areas, in every customary village; and in banjar. Messages communicated through the sounds of the kulkul commonly relate to three key events: an emergency situation, a ceremony, or a regular meeting or social event. Moreover, the kulkul sounds vary from one village to another [6].

In this paper, we focus to discuss the assembly of semantic cultural heritage knowledge specifically the Balinese kulkul in order the digital resources can be processed and manipulated in a reliable way by the computer program. Moreover, the assembly of the semantic resources is involved not only the knowledge engineers but also the knowledge of expert which is the community who possess and understand the cultural heritage knowledge. 
The significance of this project is to enable the Balinese cultural heritage knowledge specifically the kulkul system available in the explicit form in which other can be involved to extend the knowledge.

\section{The Semantic Web}

In the early days, the goal of the Internet was to push the available contents to the audience, where the contents usually comprised a collection of Web documents. The flow of information at that time was like a one-way street, where users only read the available content provided by the Web site provider without any interaction between the providers and the users. However, today the Internet users not only use the Web to retrieve information, but also to create contents. Furthermore, the interaction between Internet users is also accelerating through the growth of social networking platforms such as Facebook, Tweeter, Linkedln, and many others.

The Internet is today facing a problem with the increase in data and information published in the form of unstructured data, and mainly in the form of user-generated content. Computers can process and parse the Web pages' layouts, headers, or hyperlinks. However, computers have no reliable way to process the available data semantically. Web content is designed for human consumption, and it is purely display-oriented; it is hard for computer programs to process and manipulate the meaning of those contents automatically. However, the Semantic Web technology comprises a collection of standards and technologies that allows Web documents to be shared and reused across applications. It enables machines to process the published data meaningfully [7].

The Semantic Web is an extension of the current Web, in which all information provided on it has a well-defined meaning, enabling both computers and humans to work together. The Semantic Web does not just contain simple relationships comprising hyperlinks between media objects, such as Web pages, images, audio, text, video, and so forth. Rather, the semantic web also includes the relationship between the objects, such as people, events, organisations, and places [8].

The Semantic Web layer-cake, as shown in Figure 1, illustrates the architecture of the Semantic Web. The architecture indicates that the higher-level languages use the syntax and semantics of the lower levels. The Unicode on the lower layer of the Semantic web enables international characters to be used. The uniform resource identifier (URI) is used to uniquely identify resources for all digital resources, entities, objects and relationships in the Semantic Web. The $\mathrm{XML}$ syntax is used for all Semantic Web languages such as the following:

1. Resource Description Framework (RDF): a data model as a common framework to represent metadata about Web resources [9],

2. RDF Schema: an extension of the basic RDF vocabulary.

3. Web Ontology Language (OWL), and other ontology languages [10].

In the Semantic Web, ontologies play a critical role, and are part of an essential building block infrastructure. An ontology is a set of formal terms that are used to describe and represent a specific domain. The formal terms are mainly associated with concepts or vocabulary and how they related to one another in a particular domain. Furthermore, RDF and OWL are the common representation languages that are used for ontologies in the Semantic Web. 


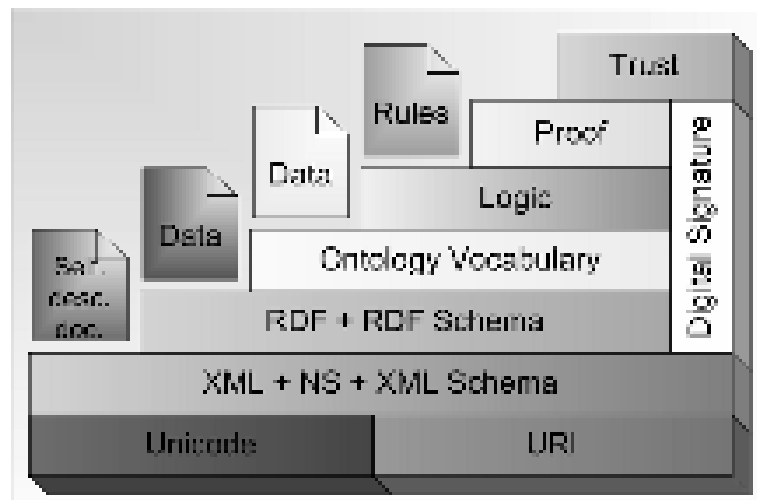

Figure 1. Tim Berners-Lee's Semantic web layer-cake. Source: Model Driven Engineering and Ontology Development, by Gasevic, et al. [10, p. 85].

\section{Ontology Approach in the Cultural Heritage Domain}

The ontologies can be useful models and tools to help represent and capture knowledge from the past, and manage and preserve cultural heritage resources in digital form [11-13]. The CIDOC CRM ${ }^{1}$ is a well-known cultural ontology that enables information integration, mediation and interchange of heterogeneous cultural heritage data and its correlation with digital library and archive information. This ontology is event-centric and focuses on the time spatial. The CIDOC-CRM has been used to abstract hundreds of schemata (80 classes and 130 relationships) in various museum disciplines. This cultural heritage ontology helps improve semantic knowledge from a distributed database of cultural heritage [14-17]. However, less than five percent of its concept base has been used by museums [18], and compatibility issues have arisen when they have been adopted [13, 19].

The advantage of using the ontology-based approach is that when digital resources are put into ontological structures, it supports better digital information retrieval and improves the user search when looking for primary sources [20]. In the cultural heritage domain, the ontology development has utilised the power of community. Members of the community are requested to participate by annotating the metadata in the ontology using a Web platform [21]. The recent adoption of an ontology-based approach in the cultural heritage domain to capture and represent the depth and richness of cultural objects and practices is acquired their knowledge in explicit forms, such as the record data available in the archive repository, data that are already in the digital form, and so forth. The digital semantic knowledge construction in term of ontology development in our study mainly involves acquisition of knowledge in the tacit form, where indepth interviews with cultural experts [6] were needed in order to understand the holistic concepts surrounding the heritage being documented.

\section{Semantic Browsing and Searching}

The Semantic Web contains not only the resources in the current Web, such as text, images, audio and video, and their simple relationships via hyperlink, but also other information involving complex relationships, such as about events, organisations, places and people, that can processed by the computer [22]. Today, research related to ontology and the Semantic Web is getting much attention from information scientists and computer scientists. Also, as a result of this, more and more applications have been developed and implemented to utilise the advantages of ontologies for organising data and for information retrieval. The most common application in the Semantic Web is the semantic browsing and semantic search engine [8, 2224].

The traditional search or Information Retrieval (IR) method commonly relies on the occurrence of words in documents, and in many cases, has high recall (the relevant items that are selected) and a low precision (the selected items that are relevant) of retrieval [23, 24]. The study by Brownlow, et al. [25] gives an example of how a semantic search can be implemented with a

${ }^{1}$ http://www.cidoc-crm.org 
good outcome for information retrieval precision. Furthermore, the ontology-based search approaches, by correspondence to the ontology structure and property types, enable the user to create and answer a complex query that is hard to handle using the traditional text-based search [26].

The development of an ontology as part of the semantic web technology aims to improve the semantic browsing and searching results. This ontology development is labour intensive and time-consuming. The crowdsourcing approach brings the benefit of sourcing human intelligence through the advantage of Web 2.0 technology to produce digital resources that can be accessed over the Internet.

\section{Ontology Development Method}

Much of the content on the Internet is designed for humans to read; however, it is hard for computer programs to interpret meaningfully [7]. Ontologies are formal structures for sharing and reuse of knowledge that provide a common understanding and interoperability between humans and machines, and are developed by small groups of experts [27, 28]. Ontologies bridge the gap to allow communication between the various application systems and facilitate the interoperability between different systems by providing a shared understanding of a domain. A set of terms to represent concepts and their specific meaning usually appears explicitly in the ontology. In the heritage domain, adopting ontologies for digital cultural heritage resources can be a useful tool to represent, capture, manage and preserve the knowledge from the past [1113]. Furthermore, ontological structures can be applied to facilitate better digital information retrieval and to improve precision when the user is looking for primary sources [29].

In our research, we developed the kulkul ontology and our development adopted the Pinto \& Martin [30] method for ontology development workflows (Figure 2), which consists of five phases:

1. Specification. At this stage, we focus on identifying the purpose of developing and scoping the kulkul ontology.

2. Conceptualisation. At this step, the conceptual model of concepts in the kulkul and domains surround the kulkul knowledge is described in the ontology to meet the specifications of the previous stage. The relations between groups of concepts are also explained here to improve and strengthen connections.

3. Formalisation. The description of the kulkul domain provided on the previous stage is formalised in writing. In the ontology, the concepts are mainly organised hierarchically by using structure relationship of "is-a (class-superclass, instance-class) or part-of".

4. Implementation. The formalised ontology from the previous step is implemented at this stage using a knowledge representation language such as the Web Ontology Language (OWL).

5. Maintenance: the implemented ontology is updated and corrected.

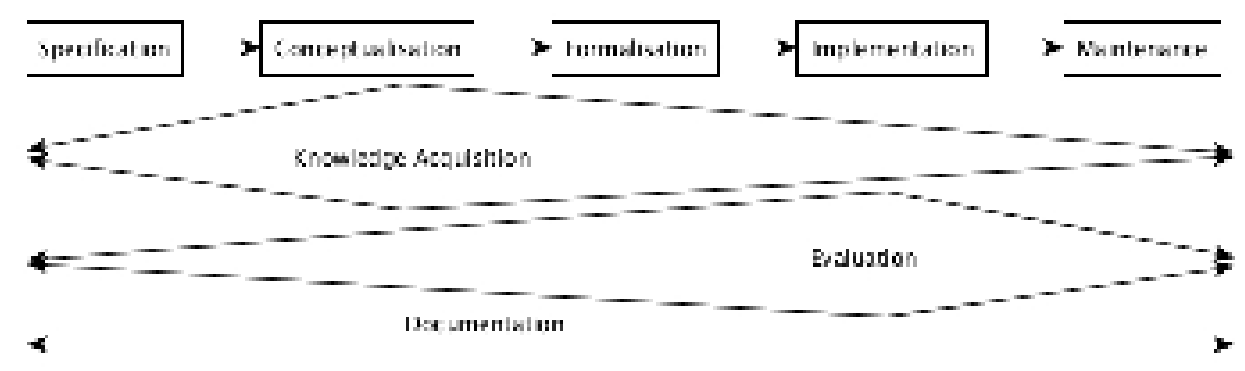

Figure 2. Ontology development workflows. Source: Digital Preservation of Cultural Heritage: An Ontology-Based Approach, by Pramartha, et al. [31]

We adopted the ontology development workflow when developing the kulkul ontology. It comprised three activities: 
1. Knowledge Acquisition. For this activity, the kulkul knowledge was acquired using interview techniques on domain experts and using the community-based crowdsourcing approach.

2. Evaluation: We technically judged the quality of the ontology.

3. Documentation: We reported what was done, how it was done and why it was done. Documentation associated with the terms represented in the ontology is particularly relevant, not only to improve its clarity but also to facilitate maintenance, use and reuse.

Given the nature of our project, we did not strictly follow its workflows and phases and employed a modified iterative and incremental approach.

\section{Knowledge Acquisition using Community-based Crowdsourcing}

Crowdsourcing is a method of acquiring contributions over the Internet from the wider public to help to solve complex problems. Crowdsourcing for cultural heritage projects typically have not involved a significant number of people; most reported cases have been relatively small collaborations with carefully chosen informants [32]. This type of crowdsourcing uses social engagement techniques and encourages a sense of public ownership and responsibility, where the volunteers do not feel taken advantage of because the projects in cultural heritage are nonprofit making [33-35]. Additionally, in the cultural domain, the participants are not looking for monetary rewards and tend to be motivated by sharing and generosity to some extent (Daniels et al., 2014).

In Bali, there are nearly 1,500 villages, around 3,600 banjars, and more than 5,000 temples that have installed kulkul. Documenting the unique and diverse kulkul-related knowledge and practices in a semantic and digital form is time-consuming and labour intensive. Accordingly, there was a strong case for a community-based crowdsourcing approach to our digital heritage project to help capture the diversity and richness of the community's knowledge about Balinese kulkul across the different villages, banjars, and temples in the island of Bali.

By adopting the community-based crowdsourcing approach, we focused on tapping the community's knowledge by gathering the relevant information about kulkul artefacts and practices from across different geographical regions. The creation of large-scale structured digital cultural resources was in the form of raw data, such as recordings of a kulkul's sound and images. This kind of information had to be first digitised before it could be submitted into the digital portal. The required kulkul contents that were uploaded into the digital portal were the specifics of the kulkul - the number of kulkul in each location, the raw material used, the direction of install, etc - and the context in which the kulkul was used, such as marriage, new baby, flood, and so on.

\section{Research Methods}

The design science research methodology (DSRM) proposed by Peffers et al. [36] offers a useful approach to carry out this research that has the goal of creating and evaluating design artefacts to address complex problems. Our study employed the DSRM shown in Figure 3. It starts with a problem-centred approach, in which the first step is the identification of the problem and the motivation for the research that has been explained in detail in our previous research [6, 31] 

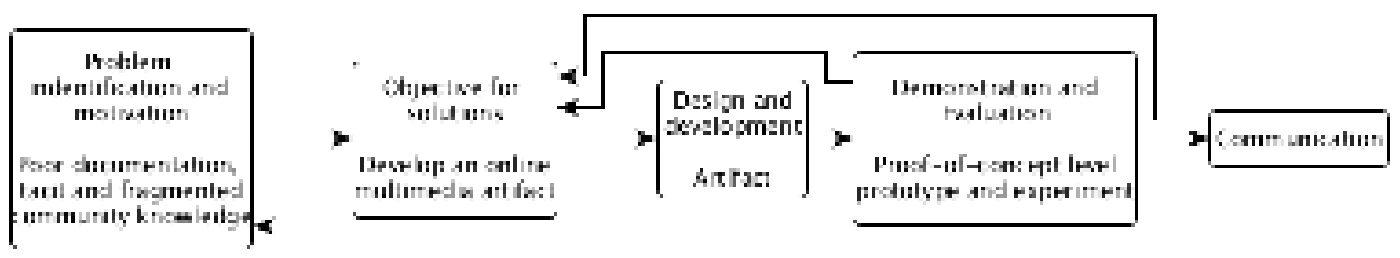

Figure 3. DSRM approach for Digital Preservation of Cultural Heritage. Source: Digital Preservation of Cultural Heritage: Balinese Kulkul Artefact and Practices, by Pramartha and Davis [6]

\subsection{Assembly the Cultural Heritage Knowledge}

As previously noted, much of the information available on the Internet is displayed in natural language and designed for humans to read. However, it is difficult for the machine to process information expressed in natural-language statements. An ontology is developed to enable a machine to process semantic statements on the Internet. The ontology is not supposed to represent an individual point of view of a particular domain, however; the information presented should be acceptable to a certain group or community. In order to be accepted by the community, standard terms and relationships should be used and created in the domain ontology. In domain ontology engineering, the terminology and the interrelationship among the terms - commonly known as the vocabulary of the application domain - is called the TBox, and the assertions of instances using the vocabulary from the TBox are known as ABox in the knowledge-based system. As an example, common terms that should be used for the TBox to describe a person include their name, birthday, address, email address, and so forth.

The following sections explain how we developed the ontology surrounding the kulkul domain, by first modelling the kulkul domain and then developing the ontology using the Protégé ontology development tool. The ontology was represented in Web Ontology Language (OWL2) and serialised into a Turtle triple format (.ttl), and then stored in the Apache Jena triple store.

\subsection{Domain Modelling}

A domain model is a representation of a set of real-world concepts that describes a selected aspect of knowledge, and the relationships among the concepts domain. A set of domain vocabulary is needed to communicate the model to the non-technical user. The consistency of the model is critical in order to represent the reality of the domain and to meet the needs of users and the developers. As previously noted, Balinese cultural heritage knowledge embodies complex interrelationships of concepts and facts; thus, it is important to carefully examine how this knowledge is made available in the digital form and how these digital resources are discovered, presented, and used in computer-based systems.

In dealing with the challenge above, it was essential to model the domain before transforming it into digital form. Shaping the kulkul domain was done at this stage, which involves developing the semantically enriched and domain-specific metadata to improve the discovery and the retrieval of the resources that could be applied using the Semantic Web technologies. The interview notes in our previous study [6] were analysed, because without such analysis the knowledge representation for the kulkul domain would not be well founded. After analysing the transcribed interviews using the thematic analytics method, we modelled the classes as:

- All entities that are families of things: for example, a family of the various kinds of temples or locations, a family of activities such as panca yadnya, symbolic classification of kulkul, and so forth.

All instances in the kulkul ontology defined as:

- All physical entities: for example, people, the name of desa adat/pakraman, banjar, raw materials. 
- All types of panca yadnya ceremonies: e.g., cremation (ngaben), meeting (sangkep).

- All kinds of hazards: e.g., flood, fire, and so forth.

- All kinds of kulkul beat or rhythm: e.g., tulud, bulus, banban, and so forth.

Much of the kulkul instances in kulkul ontology were populated by the Community Based Crowdsourcing $(\mathrm{CBC})$.

\subsection{Kulkul Ontology}

Ontologies have the flexibility to evolve and can be semantically annotated while the collection of relatively tacit and fragmented kulkul knowledge increases incrementally. In addition, a manual adjustment is also needed to maintain the knowledge in the kulkul ontology, since many parts of the knowledge evolve over time. Ontology development falls into two categories: (1) development of a new ontology [37], and (2) reuse and integration of an existing ontology [38], based on the knowledge representation needed. We developed the basic kulkul ontology based on the kulkul framework of knowledge classification, Tri Hita Karana and Desa Kala Patra [6].

The kulkul ontology provides an abstract representation of the knowledge surrounding the kulkul domain. In this study, the knowledge acquisition, evaluation, and refinement employed crowdsourcing. The use of crowdsourcing helps to reduce blind spots by integrating the views of multiple people about various topics in order to achieve a more comprehensive body of knowledge, and also enhances the probability that the community will accept the ontology [39]. In ontology engineering, a domain ontology is a formal representation of knowledge in a specific domain. The knowledge is represented with concepts (classes), relations (object property and data property) and individuals (instances or objects) that are typically grounded in a description logic and implemented in the Web Ontology Language (OWL). The key kulkul concepts or classes, properties, relationships, and example instances were created using the Protégé ${ }^{2}$ ontology editor (Figure 4) and utilised the ontology representation OWL2 language. A visual representation of classes and subclasses in the kulkul ontology is shown in Figure 5, and it based on the kulkul specification and features that we developed in our previous study [6]
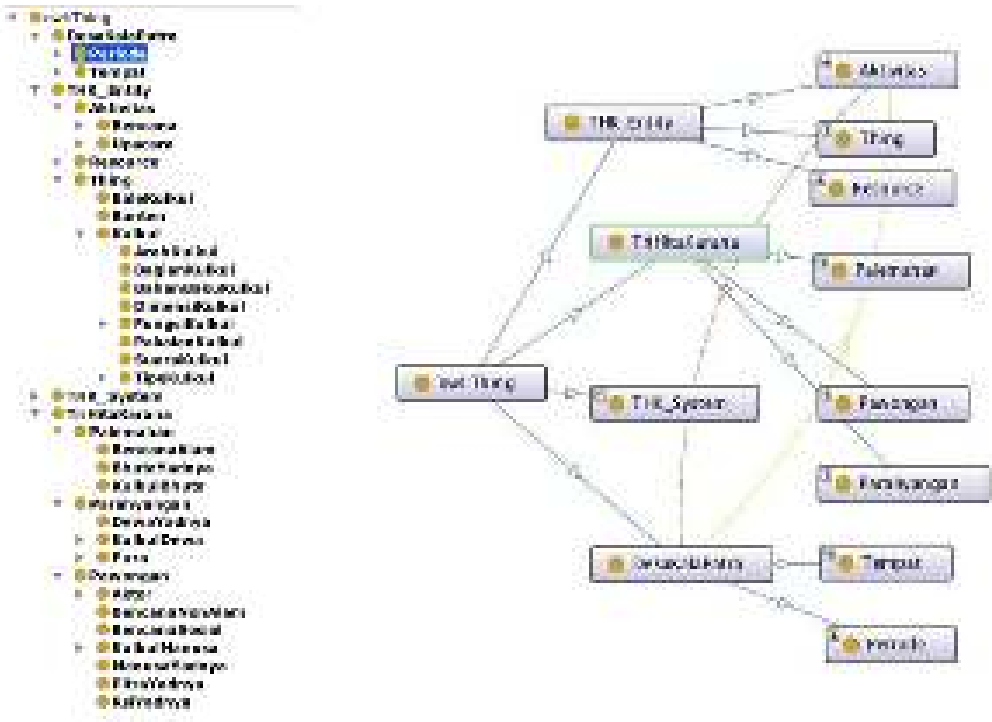

Figure 4. Kulkul ontology development using the Protégé ontology editor. 


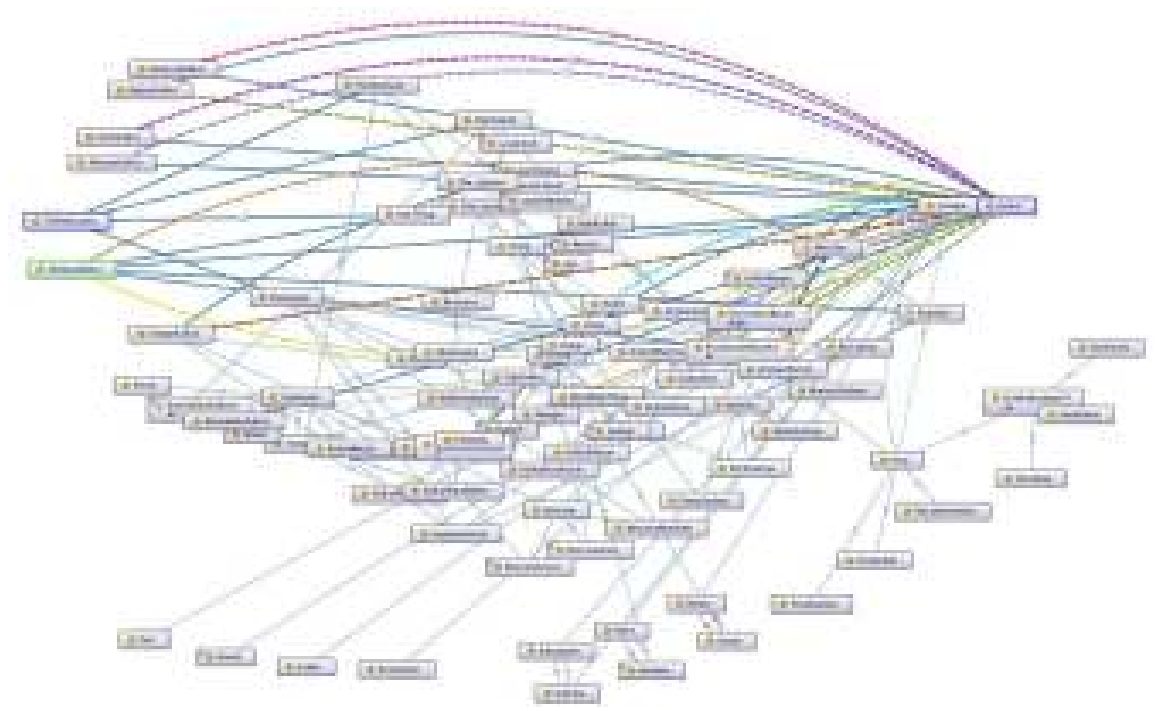

Figure 5. Visualisation of the classes and subclasses in the kulkul ontology.

Figure 6 shows a visual representation of one kulkul instance (Kulkul Banjar Adat Ubud Kaja) which is owned by banjar instance (Banjar Adat Ubud Kaja) which is a part of the regency instance (Gianyar). The visual representation in Figure 5 was translated into the Web Ontology Language (OWL) representation, to which Turtle triple syntax serialisation (ttl) was applied for easy readability of information representing the space (desa) of our ontology (shown in OWL below). We used the rdfs:label localisation to support other languages (e.g., English, Bahasa, and Balinese). Further, transitive properties (isPartof) were used to express the relationships between individuals in the classes of banjar, desa adat or desa pakraman, district, and regency.

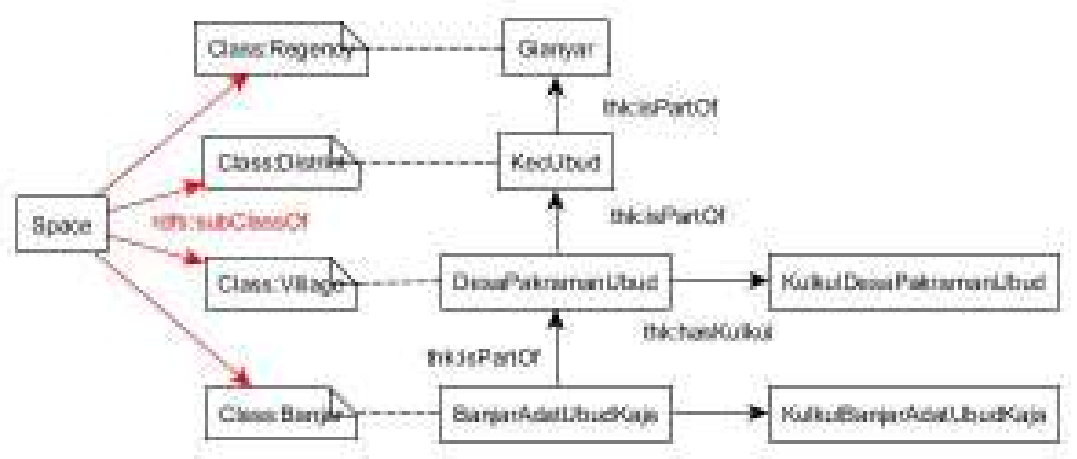

Figure 6. Visual representation of one kulkul instance (Kulkul Banjar Adat Ubud Kaja) in the regency instance (Gianyar).

1. @prefix thk: <http://dpch.oss.web.id/Bali/TriHitaKarana.owl\#>.

2. @prefix owl: <http://www.w3.org/2002/07/owl\#>.

3. aprefix rdf: <http://www.w3.org/1999/02/22-rdf-syntax-ns\#>.

4. @prefix rdfs: <http://www.w3.org/2000/01/rdf-schema\#>.

5. thk:isPartof rdf:type owl:ObjectProperty ,

6. owl:TransitiveProperty.

7. thk:BanjarAdatUbudKaja rdf:type thk:Banjar,

8. owl: NamedIndividual ;

9. thk:haskulkul thk:KulkulBanjarUbudKaja;

10. thk:isPartof thk:DesaPakramanUbud.

11. thk:DesaPakramanUbud rdf:type thk:Desa , 
12. Owl:NamedIndividual;

13. thk:hasKulkul thk:kulkulDesaPakramanUbud;

14. thk:isPartof thk:KecUbud.

15. thk:Desa rdf:type :Class ;

16. rdfs:label "Village"@en,

17. "Desa"@id.

18. thk:KecUbud rdf:type thk:Kecamatan,

19. Owl:NamedIndividual ;

20. thk:ispartof thk:Gianyar.

21. thk:Kecamatan rdf:type :Class ;

22. rdfs:label "District"@en,

23. "Kecamatan"@id.

24. thk:Gianyar rdf:type thk:Kabupaten,

25. owl: NamedIndividual.

26. thk:Kabupaten rdf:type :Class ;

27. rdfs:label "Regency"@en,

28. "Kabupaten"@id ;

29. rdfs:subclassof thk: Space.

An example to perform a semantic search to find all kulkul banjar that belong to the Gianyar regency, we can execute a SPARQL query (Figure 7) against the RDF triple store based on the kulkul ontology by utilising the SPARQL 1.1 property path expression "isPartof*". SPARQL query on the triple store endpoint is shown in Figure 7.

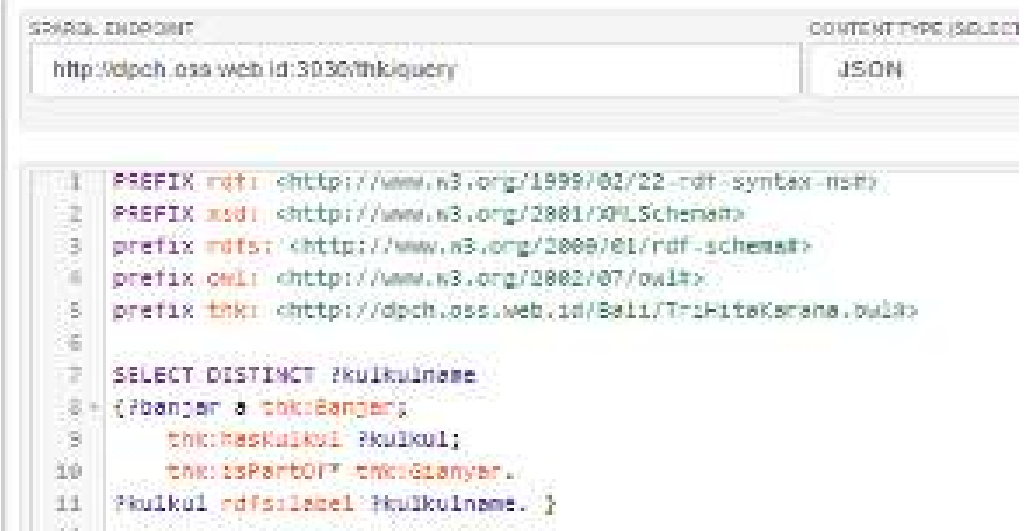

Figure 7. SPARQL query executed on the Jena Fuseki triple store endpoint.

By following the path on the kulkul ontology, the system can easily process the SPARQL query and the semantics of the digital resources and recall with high precision all instances of kulkul in the class of banjar that belong to the Gianyar regency (see the result in Figure 8).

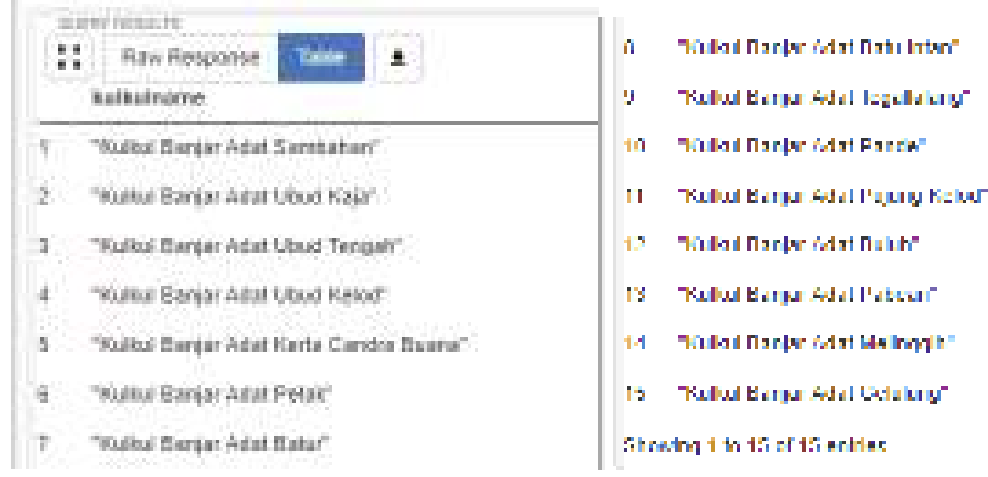

Figure 8. SPARQL query against RDF triple store. 
In the kulkul ontology that we designed, we also capture and represent the pura kahyangan tiga, and these temples relate to the desa adat or desa pakraman. The pura kahyangan tiga comprises three types of temples, to worship the gods Brahma (pura desa), Wisnu (pura puseh) and Ciwa (pura dalem). These temples are owned by every desa adat or desa pakraman in Bali, and the visualisation of this relationship is represented in Figure 9.

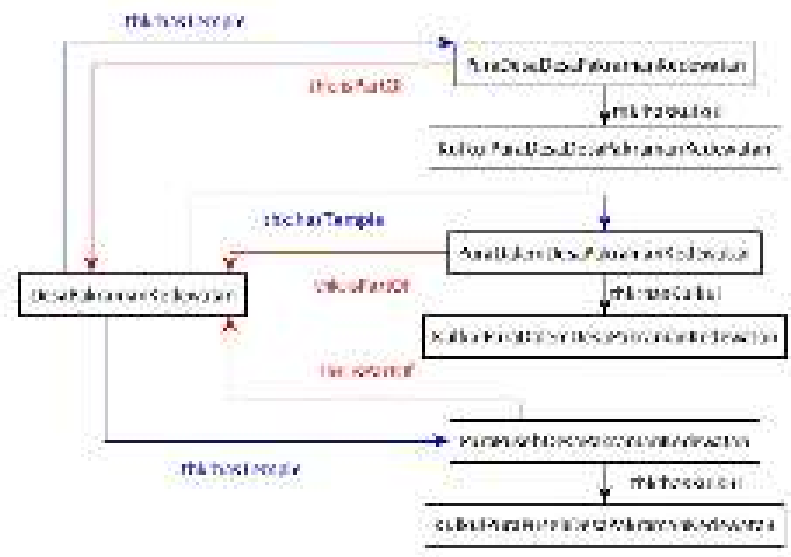

Figure 9. Relationship of desa adat or desa pakraman and pura kahyangan tiga.

The visual representation of the pura kahyangan tiga above is then constructed into the kulkul ontology and expressed in the OWL, as shown below. Transforming the kulkul knowledge into OWL format allows us to validate the basic kulkul ontology in the Protégé ontology editor using an add-in HermiT ${ }^{3}$ OWL reasoner tool. After we finished determining all related concepts (class), subclasses, and their interrelationships in the kulkul ontology, and serialised them into Turtle Triple format (.ttl) (see example below) using the Protégé Ontology Editor, we loaded them into the Jena Fuseki triple store and created 1543 triples.

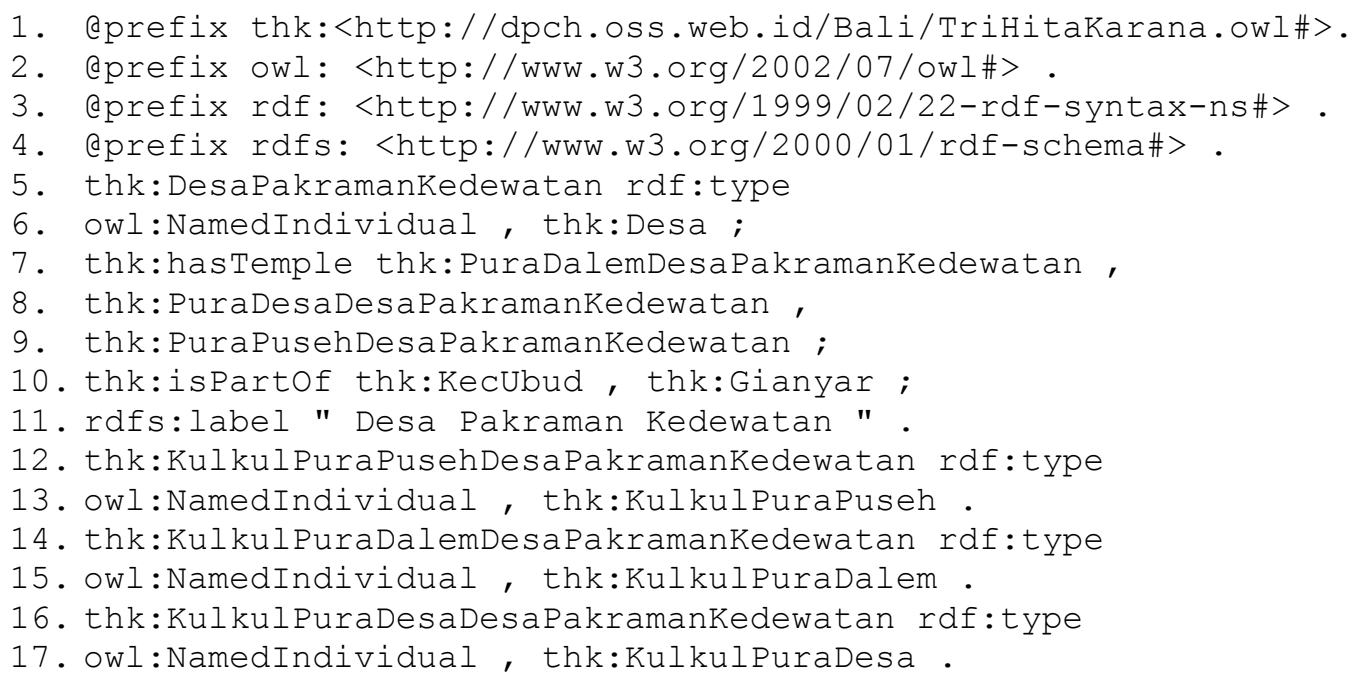

\section{Conclusion}

We have presented the details of our research to assembly the semantic cultural heritage knowledge specifically the Balinese traditional communication system (kulkul). Our contributions include the method to develop the kulkul ontology to represent the knowledge that can be processed and manipulated by the computer program. This semantic resource currently available online so that public can participate and contribute to expanding the digital resource.

${ }^{3}$ http://www.hermit-reasoner.com/ 


\section{References}

[1] G. Davison, "Patrimony to pastiche," The heritage reader, Routledge, Abingdon, pp. 3141, 2008.

[2] D. C. Harvey, "Heritage Pasts and Heritage Presents: temporality, meaning and the scope of heritage studies," International Journal of Heritage Studies, vol. 7, no. 4, pp. 319-338, 2001/01/01 2001.

[3] M. McCarthy, "Historico-geographical explorations of Ireland's heritages: Towards a critical understanding of the nature of memory and identity," in Ireland's Heritages: Routledge, 2017, pp. 3-51.

[4] Y. Ahmad, "The Scope and Definitions of Heritage: From Tangible to Intangible," International Journal of Heritage Studies, vol. 12, no. 3, pp. 292-300, 2006/03/15 2006.

[5] D. Munjeri, "Tangible and Intangible Heritage: from difference to convergence," Museum International, vol. 56, no. 1-2, pp. 12-20, 2004.

[6] C. Pramartha and J. G. Davis, "Digital Preservation of Cultural Heritage: Balinese Kulkul Artefact and Practices," in Digital Heritage. Progress in Cultural Heritage: Documentation, Preservation, and Protection: 6th International Conference, EuroMed 2016, Nicosia, Cyprus, October 31 - November 5, 2016, Proceedings, Part I, M. Ioannides et al., Eds. Cham: Springer International Publishing, 2016, pp. 491-500.

[7] T. Berners-Lee, J. Hendler, and O. Lassila, "The Semantic Web," Scientific American, pp. 34-43, 2001.

[8] M. Albanese, A. D'Acierno, V. Moscato, F. Persia, and A. Picariello, "A Multimedia Semantic Recommender System for Cultural Heritage Applications," in Semantic Computing (ICSC), 2011 Fifth IEEE International Conference on, 2011, pp. 403-410.

[9] F. Gandon and G. Schreiber. (2014, 08 August). RDF 1.1 XML Syntax. Available: https://www.w3.org/TR/rdf-syntax-grammar/

[10] D. Gasevic, D. Djuric, and V. Devedzic, Model driven engineering and ontology development, 2nd ed. Berlin: Springer, 2009, pp. xxi, 378 p.

[11] M. Doerr, "The CIDOC conceptual reference module: an ontological approach to semantic interoperability of metadata," Al magazine, vol. 24, no. 3, p. 75, 2003.

[12] I. Jurisica, J. Mylopoulos, and E. Yu, "Ontologies for knowledge management: an information systems perspective," Knowledge and Information systems, vol. 6, no. 4, pp. 380-401, 2004.

[13] T. Stasinopoulou et al., "Ontology-based metadata integration in the cultural heritage domain," in Asian Digital Libraries. Looking Back 10 Years and Forging New Frontiers: Springer, 2007, pp. 165-175.

[14] L. Hong-Zhe, H. Bao, W. Jing, and F. Jun-Kang, "An Information Flow Based Approach to Semantic Integration of Distributed Digital Museums," presented at the International Conference on Machine Learning and Cybernetics, 2006, 13-16 Aug. 2006, 2006.

[15] T. Guoxin, H. Tinglei, and Z. Zheng, "A Knowledge Modeling Framework for Intangible Cultural Heritage Based on Ontology," presented at the Second International Symposium on Knowledge Acquisition and Modeling, 2009. KAM '09, Nov. 30 2009Dec. 1 2009, 2009.

[16] L. Hong-Zhe, "Global Ontology Construction for Heterogeneous Digital Museums," presented at the International Conference on Machine Learning and Cybernetics, 2007, 19-22 Aug. 2007, 2007.

[17] C. Kakali et al., "Integrating Dublin Core metadata for cultural heritage collections using ontologies," in International Conference on Dublin Core and Metadata Applications, 2007, pp. pp. 128-139. 
[18] M. Doerr and D. lorizzo, "The dream of a global knowledge network: A new approach," J. Comput. Cult. Herit., vol. 1, no. 1, pp. 1-23, 2008.

[19] C. Soyoung and K. Jung Wha, "Constructing a Foundation for Semantic Structure of Korean Heritage Information: A Study on Creating a Substructure of Korean Heritage Portal by Implementing CIDOC CRM," in Semantic Computing (ICSC), 2010 IEEE Fourth International Conference on, 2010, pp. 513-518.

[20] S. A. M. Nasir and N. L. M. Noor, "Integrating Ontology-based Approach in Knowledge Management System (KMS): Construction of Batik Heritage Ontology," in Science and Social Research (CSSR), 2010 International Conference on, 2010, pp. 674-679: IEEE.

[21] V. Lombardo and A. Pizzo, "Ontologies for the metadata annotation of stories," in 2013 Digital Heritage International Congress (DigitalHeritage), 2013, vol. 2, pp. 153-160.

[22] R. Guha, R. McCool, and E. Miller, "Semantic search," in Proceedings of the 12th international conference on World Wide Web, 2003, pp. 700-709: ACM.

[23] Y. Lei, V. Uren, and E. Motta, "Semsearch: A search engine for the semantic web," in EKAW, 2006, vol. 4248, pp. 238-245: Springer.

[24] A. Duke, T. Glover, and J. Davies, "Squirrel: An advanced semantic search and browse facility," The semantic web: research and applications, pp. 341-355, 2007.

[25] R. Brownlow, S. Capuzzi, S. Helmer, L. Martins, I. Normann, and A. Poulovassilis, "An Ontological Approach to Creating an Andean Weaving Knowledge Base," J. Comput. Cult. Herit., vol. 8, no. 2, pp. 1-31, 2015.

[26] T. Tran, P. Cimiano, S. Rudolph, and R. Studer, "Ontology-based interpretation of keywords for semantic search," The Semantic Web, pp. 523-536, 2007.

[27] D. Fensel, Ontologies. Springer, 2001.

[28] T. R. Gruber, "A translation approach to portable ontology specifications," Knowledge acquisition, vol. 5, no. 2, pp. 199-220, 1993.

[29] H. Lin and J. Davis, "Computational and crowdsourcing methods for extracting ontological structure from folksonomy," in The Semantic Web: Research and Applications: Springer, 2010, pp. 472-477.

[30] H. S. Pinto and J. P. Martins, "Ontologies: How can They be Built?," (in English), Knowledge and Information Systems, vol. 6, no. 4, pp. 441-464, 2004/07/01 2004.

[31] C. Pramartha, J. G. Davis, and K. K. Y. Kuan, "Digital Preservation of Cultural Heritage: An Ontology-Based Approach," in The 28th Australasian Conference on Information Systems, Hobart, Australia, 2017, pp. 1-12, 2017.

[32] J. Oomen and L. Aroyo, "Crowdsourcing in the cultural heritage domain: opportunities and challenges," presented at the Proceedings of the 5th International Conference on Communities and Technologies, Brisbane, Australia, 2011.

[33] S. L. Alam and J. Campbell, "Crowdsourcing motivations in a not-for-profit GLAM context: the Australian newspapers digitisation program," in ACIS 2012: Location, location, location: Proceedings of the 23rd Australasian Conference on Information Systems 2012, 2012, pp. 1-11: ACIS.

[34] L. Carletti, "A grassroots initiative for digital preservation of ephemeral artefacts: the Ghostsigns project," 2011.

[35] T. Owens, "Digital Cultural Heritage and the crowd," Curator: The Museum Journal, vol. 56, no. 1, pp. 121-130, 2013.

[36] K. Peffers, T. Tuunanen, M. A. Rothenberger, and S. Chatterjee, "A design science research methodology for information systems research," Journal of management information systems, vol. 24, no. 3, pp. 45-77, 2007.

[37] M. Cristani and R. Cuel, "A survey on ontology creation methodologies," International Journal on Semantic Web and Information Systems (IJSWIS), vol. 1, no. 2, pp. 49-69, 2005. 
[38] A. Gómez-Pérez and M. D. Rojas-Amaya, "Ontological Reengineering for Reuse," in Knowledge Acquisition, Modeling and Management: 11th European Workshop, EKAW'99 Dagstuhl Castle, Germany, May 26-29, 1999 Proceedings, D. Fensel and R. Studer, Eds. Berlin, Heidelberg: Springer Berlin Heidelberg, 1999, pp. 139-156.

[39] C. W. Holsapple and K. D. Joshi, "A collaborative approach to ontology design," Communications of the ACM, vol. 45, no. 2, pp. 42-47, 2002. 